\title{
Sociomateriality and Information Systems Success and Failure*
}

\author{
Karlheinz Kautz ${ }^{1}$ and Dubravka Cecez-Kecmanovic ${ }^{2}$ \\ ${ }^{1}$ University of Wollongong, School of Information Systems \& Technology, \\ Wollongong NSW 2522, Australia \\ kautz@uow. edu.au \\ ${ }^{2}$ University of New South Wales, School of Information Systems, \\ Technology \& Management, Sydney NSW 2052, Australia \\ dubravka@unsw.edu.au
}

\begin{abstract}
The aim of this essay is to put forward a performative, sociomaterial perspective on Information Systems (IS) success and failure in organisations by focusing intently upon the discursive-material nature of IS development and use in practice. Through the application of Actor Network Theory (ANT) to the case of an IS that transacts insurance products we demonstrate the contribution of such a perspective to the understanding of how IS success and failure occur in practice. The manuscript puts our argument forward by first critiquing the existing perspectives on IS success and failure in the literature for their inadequate consideration of the materiality of IS, of its underling technologies and of the entanglement of the social and material aspects of IS development and use. From a sociomaterial perspective IS are not seen as objects that impact organisations one way or another, but instead as relational effects continually enacted in practice. As enactments in practice IS development and use produce realities of IS success and failure.
\end{abstract}

Keywords: IS success, IS failure, IS development, IS assessment, sociomateriality, actor-network-theory (ANT).

\section{Introduction}

IS success and failure has been a prominent research topic since the very inception of the field. The whole Information Technology (IT) industry, as Fincham (2002) notes, loudly trumpets its successes and failures and in particular "seems perversely captivated by its own failures" (p. 1). Some examples of high-profile IS project failures include the disastrous development of 'Socrate' by the French Railways (Mitev 1996), the dramatic failure of Taurus at the London Stock Exchange (Currie 1997), the failed patient administration system at NSW Health in Australia (Sauer et al.

\footnotetext{
The argument presented in this keynote essay has subsequently been further developed in Cecez-Kecmanovic, D., Kautz, K. and Abrahall, R. "Reframing Success and Failure of Information Systems: A Performative Perspective”, to appear in MIS Quarterly, 2013.
} 
1997), and the Internal Revenue Service's development of a new US Tax Modernisation System (Nelson and Ravichandran 2001). High failure rates of IS projects and our inability to understand and explain, let alone prevent, the failures suggest that perhaps existing assumptions and approaches to IS research have not served us too well.

In 2001, the Australian subsidiary of a large multinational insurance company dealing primarily in business and life insurance, which we call Olympia, undertook to become the first insurance provider in Australia of web-based e-business services to their brokers. In 2006, the web-based information system (IS), named 'Olympiaonline' emerged as a sophisticated IS, eagerly adopted and highly praised by brokers. Olympia-online's success in the broker community created a competitive advantage for the company leading to an increase in their profit margins. However, being over time and over budget, and not delivering expected internal functionality the system was perceived as a big failure by the top business managers. That Olympia-online was considered simultaneously as a success and a failure, with both views firmly supported by evidence, is extraordinary and challenges the established understandings of IS success and failure. From a rationalist perspective IS success or failure are defined as discrete, objectively measured and definite states and outcomes contingent upon simple causation, e.g. certain technical characteristics and social factors or causally linked variables (DeLone and McLean 1992). The socio-technical and process oriented perspective assumes that there is no "objectively correct account of failure" (Sauer 1993, p. 24) or success, but it too assumes an objectified view resulting from politically and socially determined flaws and processes. Neither the rationalist nor the socio-technical process approach can explain the persisting co-existence of Olympiaonline success and failure. From a social constructivist perspective (Fincham 2002), these co-existing perceptions can be explained by conflicting subjective interpretations and discourses of relevant social groups (Bijker 1993; Bartis and Mitev 2007). Assuming 'interpretive flexibility' of IS, this perspective helps understand how different social groups attribute different meanings and construct different assessments of an existing IS. This perspective has been critiqued for black-boxing IS and for putting too much emphasis on the interpretation and signification of IS while overlooking the ways in which IS' materiality is always already implicated in its social constructions (Orlikowski 2007).

In response we propose a sociomaterial perspective of IS success and failure informed by the works of Orlikowski and Scott (2008), Latour (2005), and Law (1992, 2004) among others. While social construction focuses on performativity of language and discourses, the sociomaterial perspective focuses on IS enactment in practice that implies performativity of both discourses and technologies. We suggest that an IS assessment is not only an interpretation or social construction, but a result of IS enactments in practice that produce realities (Law 2004). If an IS can be differently enacted in different practices we should expect a possibility that such enactments can produce different realities. It is this reality making capacity of IS enactment in different practices that we propose to understand the co-existing realities of IS success and failure. When different IS enactments create multiple realities, contradicting realities of IS assessments may emerge and coexist. To substantiate our claim we draw from sociology of science and technology studies and specifically actor-network theory (ANT) (Callon 1986; Latour 2005; Law 1992, 2004) as one prominent way of dealing 
with sociomateriality of IS (Orlikowski 2007). An ANT account of the Olympiaonline grounds and illustrates the sociomaterial perspective on IS success and failure.

We first review different approaches to IS success and failure, then we introduce the key assumptions of the sociomaterial perspective. This is followed by a description of ANT in the research methodology section which leads to the ANT account of the Olympia-online development and use. The ensuing discussion focuses on the ways Olympia-online was enacted in the practices of the brokers, the developers, and the business managers, and how these different enactments created multiple, only partially overlapping realities. Finally we summarize the contributions of the sociomaterial perspective to understand the entangled, discursive-material production of IS success and failure.

\section{Literature Review and Theoretical Background}

We base our literature review on Fincham (2002) who distinguishes three perspectives on IS success and failure. The rationalist view explains success and failure as brought about by factors which primarily represent managerial and organizational features in system development and which are related through simple causation. DeLone and McLean's (1992) model of success and Lyttinen and Hirschheim's (1987) classification of the IS failure concept are well-known examples of this perspective. Numerous other studies found that social/organisational factors, rather than technical, had been dominant contributors to failure (e.g. Luna-Reyes et al. 2005; Lee and Xia 2005). Luna-Reyes et al. (2005) claim that as much as $90 \%$ of IS failures are attributed to these factors. Underlying the rationalist view is an assumption that IS success and failure are discrete states that can be identified and predicted by the presence/absence of certain factors. Although the lists of factors do not provide coherent explanations of why and how success and failure occur and rarely explain the phenomenon across different organizations, this is still the dominant view in the literature (DeLone and McLean 2003).

The process perspective addresses these shortcomings. It emphasizes organizational and social-political processes and explains success and failure as the result of a socio-technical interaction of different stakeholders with IS. Kautz and McMaster (1994) provide one example for this view; but Sauer's (1993) model of IS failure is the most comprehensive framework utilizing this perspective. Although it focuses on organizational and socio-technical processes, these are still seen to cause failure/success as discrete outcomes (Fincham 2002). The perspective remains anchored to some rational assumptions such as failure having a clear-cut impact and being objectivised as irreversible. Thus it does not cater for ambiguity in socio-political processes nor does it allow reflections on the relationship between success and failure, such as why success and failure are simultaneously attributed to the same IT artefact or how and why success is so often created out of failure.

Alternatively, Fincham (2002) puts forward a social constructivist, narrative perspective where the organizational and socio-political processes and the actions and stories accompanying it, are based on sense-making and interpretation and where IS 
success and failure are explained as a social construction. The social constructivist perspective draws attention to different viewpoints and interpretations of IS by relevant social groups thus resulting in interpretive flexibility of IT artefacts (Bijker 1993; Wilson and Howcroft 2005). Extending the social constructivist perspective with organizational power and culture, Bartis and Mitev (2008) explain how the dominant narrative of a more powerful relevant social group prevailed and disguised an IS failure as success. Mitev (2005) also proposes extending the social constructivist perspective by using ANT. Like McMaster et al. (1997) and McMaster and Wastell (2004), she utilizes ANT with its concepts of human and non-human actants interrelated in actor-networks going beyond simple explanations of technological determinism to explain success and failure. However, these accounts neglect a view of IT artefacts as more than social constructions, but less than reified physical entities (Quattrone and Hopper 2006).

This view emphasises the sociomaterial nature of an IT artefact: its agency resides neither in a technology nor in a human actor, but in a chain of relations between human and technological actants. With its rich theoretical background it inspired us to propose a fourth, sociomaterial perspective on IS success and failure which goes beyond social construction and the representational perspective where IS success and failure are represented either by objective measures or by subjective perceptions of social actors assuming that representations and the objects they represent are independently existing entities. The sociomaterial perspective assumes inherently inseparable sociality and materiality of IS (Orlikowski 2007; Orlikowski and Scott 2008). It introduces a way of seeing an IS development and use and its assessment not only discursively constructed but also materially produced and enacted in practice. Exemplified by ANT the sociomaterial perspective assumes a relational ontology involving human and non-human actors that take their form and acquire their attributes as a result of their mutual relations in actor-networks. Its relationality "means that major ontological categories (for instance, 'technology' and 'society', 'human' and 'nonhuman') are treated as effects or outcomes, rather than as explanatory resources" (Law, 2004, p. 157); IS development and use can thus be seen as relational effects performed within actor-networks. We focus on the performed relations and the phenomena of IS development, use and assessment as the primary units of analysis and not on a given object or entity. In following Barad (2003) we understand phenomena as ontologically primitive relations without pre-existing relata which exist only within phenomena; they "are the ontological inseparability of agentially intra-acting "components" (p. 815). The notion of intra-action constitutes an alteration of the traditional notion of causality. Intra-actions within a phenomenon enact local agential separability and agential cuts which effect and allow for local separation within a phenomenon. Hence, within inseparable phenomena agential separation is possible. Performativity then is understood as the iterative intra-activity within a phenomenon (Barad 2003). This perspective allows us to identify and to better understand IS-related phenomena by investigating them in their inseparability as well as in their local separability, intra-action and agency through agential cuts, both in the context of utilization and the development of IS. Table 1 summarizes the four perspectives on IS success and failure. 
Table 1. IS success and failure Perspectives (extended from Fincham 2002)

\begin{tabular}{|c|c|c|c|}
\hline Perspective & $\begin{array}{l}\text { Form of organiza- } \\
\text { tional behavior and } \\
\text { action }\end{array}$ & $\begin{array}{l}\text { Methodological } \\
\text { focus }\end{array}$ & $\begin{array}{l}\text { IS success and } \\
\text { failure seen as }\end{array}$ \\
\hline Rationalist & $\begin{array}{l}\text { Managerial and } \\
\text { organizational } \\
\text { structures and goals }\end{array}$ & $\begin{array}{l}\text { Simple cause and } \\
\text { effect }\end{array}$ & $\begin{array}{l}\text { Objective and } \\
\text { polarized states - } \\
\text { outcomes of tech- } \\
\text { nological and so- } \\
\text { cial factors }\end{array}$ \\
\hline Process & $\begin{array}{l}\text { Organizational and } \\
\text { socio-political } \\
\text { processes }\end{array}$ & $\begin{array}{l}\text { Socio-technical } \\
\text { interaction }\end{array}$ & $\begin{array}{l}\text { Socially and polit- } \\
\text { ically defined - } \\
\text { outcomes of orga- } \\
\text { nizational } \\
\text { processes and } \\
\text { flaws }\end{array}$ \\
\hline $\begin{array}{l}\text { Constructivist, } \\
\text { narrative }\end{array}$ & $\begin{array}{l}\text { Organizational and } \\
\text { socio-political } \\
\text { processes; symbolic } \\
\text { action, themes, } \\
\text { plots, stories }\end{array}$ & $\begin{array}{l}\text { Interpretation and } \\
\text { sense-making of } \\
\text { relevant social } \\
\text { groups; narrative, } \\
\text { rhetoric and per- } \\
\text { suasion }\end{array}$ & $\begin{array}{l}\text { Social construc- } \\
\text { tions, implying } \\
\text { interpretive flex- } \\
\text { ibility of IS }\end{array}$ \\
\hline $\begin{array}{l}\text { Sociomaterial, } \\
\text { such as ANT }\end{array}$ & $\begin{array}{l}\text { A relational view of } \\
\text { organizations and IS } \\
\text { as sociomaterial } \\
\text { arrangements of } \\
\text { human and non- } \\
\text { human actors }\end{array}$ & $\begin{array}{l}\text { Emergence and } \\
\text { reconfiguration of } \\
\text { IS development } \\
\text { and use actor- } \\
\text { networks; enact- } \\
\text { ments of IS in } \\
\text { practice }\end{array}$ & $\begin{array}{l}\text { IS enactment and } \\
\text { production of mul- } \\
\text { tiple realities in } \\
\text { practice }\end{array}$ \\
\hline
\end{tabular}

The sociomaterial perspective helps us turn the epistemological question - how can we find out and predict whether an IS is 'true' success or failure? - into ontological ones: How does IS success or failure come about? How is an IS enacted in practice? How do these enactments produce different realities, including the coexisting assessments of IS success and failure? To answer these questions we do not take the social factors or processes or technology as given. Instead we investigate the actors and actants as they enrol and perform in heterogeneous actor-networks; we follow the emergence and reconfiguration of actor-networks and the ways IS enactments in practice are negotiated and realities are created. Within the sociomaterial perspective IS are seen as sociotechnical relational actants or actor-networks that come into being through enactment in practice. This enactment involves mutually intertwined discursive and material production. Different perceptions and interpretive flexibility of an IS, as advocated by social constructivists, reveal only one side of a coin - the discursive production of IS. The sociomaterial perspective broadens our gaze by attending to the ways in which IS are enacted and performed simultaneously and inseparably socially, discursively and materially, technologically in relations in practice. 
We acknowledge that being performed and enacted in different practices IS are creating multiple realities and there are various possible reasons why an IS enactment creates one kind of reality rather than another.

\section{Research Methodology}

ANT embodies several key aspects of sociomateriality relevant to our examination of IS success and failure. ANT does not make a priori assumptions about the nature of actors or the ways they act to make up their worlds. Any human or non-human actor can be involved in relations, form alliances and pursue common interests in an actornetwork. An IS development and implementation as well as utilization endeavour can be seen as emergent, entangled, sociomaterial actor-networks created by aligning interests of developers, users, documents, methodology and technologies. The alignment of interests within an actor-network is achieved through the enrolment of allies and translation of their interests in order to be congruent with those of the network (Walsham 1997). The actors enrolled in a network have "their own strategic preferences [and] the problem for the enroller therefore is to ensure that participants adhere to the enroller's interests rather than their own" (McLean and Hassard 2004, p. 495). Translation can be achieved through scripts, which influence actors to act in a particular way so as to achieve an actor-network's goals.

An actor-network does not imply existence of its constituting actors, but rather sees them constituted by the relations they are involved in. It is the morphology of relations which tells us what actors are and what they do (Callon 1999). The network changes through enrolment of new actors, creation of new alliances and changing relations among its actors. With an increasing alignment of interests and strengthening of relations an actor-network becomes more stabilized. This is what actornetworks strive for. However, they do not necessarily succeed; they may get weaker, break up and disappear. How they strengthen and stabilize or break up and dissolve is an interesting theoretical question with serious practical implications.

In line with other IS researchers who adopted ANT to provide robust accounts of the production and reconfiguration of relations in the development and implementation of IS seen as actor-networks (see e.g. Mitev 1996; Vidgen and McMasters 1997; Walsham and Sahay 1999; Holmström and Robey 2005) we develop an ANT account of the Olympia-online project. Without many prescriptions in the literature about how to do that we focused on practices of IS development and use and adopted the general advice 'follow the actors'. One member of the research team spent 6 months as staff on the Olympia-online development team. This was useful for gaining knowledge of the company, its management and IS development processes and for subsequent examination of actors and actor-networks. However the actual ANT study of the project started after her contract in the company had been concluded.

We initially focused on the development team, but then expanded our view as we traced enrolments, actors and their associations. The tracing of associations and identification and exploration of the creation and emergence of actor-networks led us to new human and non-human actors in the project team and beyond - to managers and brokers; the e-business platform, the insurance industry, etc. At some point following the actors and tracing further associations had to stop. We had to learn when and 
where to 'cut the network', in the words of Barad (2003) make agential cuts. "The trick is", says Miller (1996, p. 363), "to select the path you wish to follow, and those which you wish to ignore, and do so according to the assemblage you wish to chart".

During our study we encountered 46 human actors, engaged with technologies, important documents and other non-human actors, at different stages and locations. We had informal conversations with 21 human actors, traced additional 13 that played a role in the past but had left, and formally interviewed 12: 2 architects, 2 application developers, a data migration developer, a senior business analyst, a business project manager, a test team leader, a business expert underwriting, a business expert liaising with brokers, a senior IS executive and a senior General Insurance (GI) business manager. Documents that played an important role included a business plan, a business case and scope document, business information requirements, change requests, test plans, test cases, and project reports; important technology actants included the webbased e-business platform, a rule-based software engine, mainframe resources, application programs, interface designs and programs, and IT architecture.

The empirical data helped us reveal and reconstruct the trajectories of the actornetworks. They often exposed tensions and the political nature of the issues discussed. In the interviews as well as in the informal discussions we let the actors make sense of the project, their experiences and various events. Following the actors and their relations emerging in the project as well as executing, identifying and analysing agential cuts helped us map the creation and reconfiguration of several actor-networks. This was an iterative process that involved describing, analysing and revising these actornetworks, using ANT inquiry to reveal the inner workings of various actors and their networks e.g. enrolling actors into a network and ensuring that members of a network align with the enroller's interests; using delegates such as technology or documents to exert power and influence others. In this way we exposed different enactments of Olympia-online in practice and the ways in which they produced multiple realities including the coexisting and controversial assessments of its success and failure.

\section{The Company Olympia and ITS Olympia-Online Project}

Olympia-online was an industry-first e-business system in the Australian insurance market that transacted the company's insurance products directly to brokers over the web. Knowledge about building such systems was scarce in both the insurance and the IT industry. The final system was highly innovative in the way it represented the company's insurance products and enabled on-line engagement and interaction with brokers, who as intermediaries sell these products to customers. The withdrawal of the top management support for further Olympia-online development created a worrying situation for the company. Olympia-online was vital to the company since all its business was mediated through brokers; unlike other insurance companies, it had no direct contact with individual customers. System developers in particular were acutely aware that the lack of top managers' commitment to continue funding its further development would put the company at risk and seriously threaten its future competitiveness. 
Prior to the development of Olympia-online Olympia was not seen as a major competitor in the Australian general insurance market. All e-business in the Australian Insurance Industry was conducted via 'BrokerLine', an outdated mainframebased electronic platform, run by Telcom, an Australian telecommunications company. Early in 2001 Telcom announced that they were ceasing operation of BrokerLine and that all companies were required to move their business operations to a new web-based platform 'Horizon'.

Most insurance companies transacted their business both directly with individual businesses and via brokers, being reciprocally aligned with both; thus Olympia was particularly vulnerable to the platform change. Fearing loss of their business and simultaneously recognising opportunities of a new web-based platform, Olympia's GI Business Division and the Strategy \& Planning Division went about putting together a business case for the development of a new web-based IS, Olympia-online. They inscribed Olympia's interest and its new strategy into the Olympia-online Business Plan, which became an effective instrument for enrolling the Information Services Department (ISD) into the new IS development actor-network. This inscription was strong enough to motivate ISD to attempt alignment with Horizon and the brokers. As a key actor in the new emerging actor-network ISD was charged with the responsibility to develop a concrete solution - a new IS that enabled transecting with brokers via Horizon's web-based platform as described in the Business Case documentation. With a prospect of becoming the only channel through which Olympia would interact with brokers to sell its products, Olympia-online development became a strategic IS project in the company.

Olympia-online was a new type of IS in the insurance industry. Without in-house experience or skills and resources, Olympia searched for a supplier with the capabilities to develop Olympia-online thus attempting to enrol an actor to ensure Olympia's alignment with Horizon. Based on the scripts expressed in the Business Case documentation, two companies bided for a contract with Olympia thus attempting to forge an alignment with the company. This process was mediated through Olympia's Senior ISD Architect. The company HighTech was successful as it did promise delivery within the desired timeframe and a fixed-price contract. Developers from HighTech succeeded in demonstrating that the Emperor, a proprietary rules engine of which HighTech was the sole reseller in Australia, was an appropriate technology upon which the new system could be built. By successfully aligning themselves with Olympia's strategy inscribed in the Business Plan, HighTech and Emperor became enrolled into the Olympia-online development actor-network. The signed contract marked the beginning of Phase 1 of the Olympia-online development. Phase 1 development began with initial requirements gathering sessions by the HighTech team.

\subsection{Phase 1 Olympia-Online Development}

The Hightech team had to understand the insurance business, the data and rules in insurance products, as they had no experience in insurance applications. Once development was underway, several problems emerged. It became clear to ISD staff that HighTech's developers had not grasped the breadth and depth of the problem, resulting in the project running seven months over schedule. In retrospect, the Senior ISD Architect involved in commissioning HighTech noted that the HighTech team “didn't 
understand the problem at hand" and underestimated its complexity, costs and the required development time. During this time, ISD staff realized that Emperor "was not the right engine for Olympia-online's purpose". When used to model insurance products and their complex business rules, Emperor exhibited severe limitations and rigidity. As a result the design of the application software was cumbersome and complex, requiring the development of extra software components to compensate for its insufficiency. Instead of working with a rule engine that had a "natural fit" with insurance products as HighTech developers initially claimed, the ISD team discovered a "dramatic misfit". Emperor was misaligned with Olympia-online's objectives.

In the initial Olympia-online development actor-network there were several attempts of alignment and many translations going on. The HighTech Project Manager attempted alignment with the Senior ISD Architect and at the same time exerted power over the Olympia team's work by making design decisions regarding the use of Emperor in the system's development based on his architect's advice. While he never fully disclosed Emperor's limitations for modelling insurance products, he successfully negotiated and established its key role in Olympia-online.

As the relations between the software components built on Emperor and those on the mainframe grew tighter the implications for the functionality and efficient operations of Olympia-online became more evident. The relations between the HighTech team and the Olympia team, Emperor and the mainframe system were highly contentious, yet critical for the development of Olympia-online. By insisting on Emperor as a platform for the application software the HighTech Project Manager by way of his Architect ensured that his company's interests were inscribed in the software. The more this software became dependent on Emperor the more this actor-network became irreversible ${ }^{1}$.

During Phase 1 the development actor-network was continually reconfigured through a series of translation processes that strengthened some alignments but failed others, and thus prevented its stabilization. The two actors overseeing this work, the HighTech Project Manager and the Olympia Head Architect, had trouble ensuring the delivery of the system with the specified functionality on time. At the beginning of 2002, as Phase 1 was significantly delayed, the GI Business Division was anxious to announce to the brokers that the new system was ready for use. They publicly promised that full functionality would be available by mid 2002 which upset ISD staff. When finally delivered to the brokers, despite nine months delay, Olympia-online was a great success: brokers were delighted with the new technology. The web-based specification of insurance products enabled brokers' flexible interaction with Olympia while selling its products to customers. Able to focus on customer needs and tailor products to meet these needs brokers gradually changed their work processes. Their enactment of Olympia-online produced different practices in transacting business with Olympia and its customers.

This first implementation of Olympia-online however exposed numerous technical problems, slow performance, frequent crashes and defects. As a result ISD staff had

\footnotetext{
${ }^{1}$ Phase 1 was further complicated by yet another translation process going on in the development of the interface between Olympia-online and Horizon. This was carried out by another third party, that is, another actor-network which we did not dig further into as this was not relevant for answering our research question.
} 
huge difficulties in maintaining it. Furthermore, its design was not modular and hence the system lacked the ability to be scaled to Olympia's future needs. ISD staff and their Senior Architect in particular, believed that Olympia-online's technical failures were caused primarily by the use of Emperor that "could not easily model complex insurance products". The Emperor's rule engine, they found out too late, was originally developed for specification of physical products such as machinery and had never been used before for products as complex as insurance. The enrolment of HighTech and Emperor into the Olympia-online development was, in their view, a wrong decision. In the meantime, the broker community strengthened their relation with Olympia and communicated its satisfaction with the system to the GI Business Division. Being first-to-market Olympia-online attracted new brokers and boosted business so GI revenue for business insurance grew significantly. Through their contacts with the HighTech Project Manager GI Business Managers believed that Emperor was the key contributor to the success. They were not aware of the problems experienced in the development nor did they realise the full extent of the system's technical failures and instability in operations. They thought the Olympia-online system was an unqualified success.

Based on this market success, GI Business Managers, in discussions with HighTech, made the decision to purchase \$1 million worth of Emperor Licenses such that the existing system could be extended and more systems and products could be developed in the future. This decision was made without consulting ISD staff, as their mutual relations had deteriorated by that time. In the meantime, ISD staff were busy struggling to maintain an unstable system and respond to numerous defects. When Olympia-online became so unstable that its maintenance and use could no longer be sustained, ISD proposed Phase 2 of the Olympia-online development. Since GI managers had already spent $\$ 1$ million on licensing it ISD had no other option but to continue the further development of Olympia-online with Emperor.

\subsection{Phase 2 Olympia-Online Development}

Phase 2 started mid 2003 and the system went live in April 2005 with one major goal being to bring the Olympia-online development and knowledge in house, since "it was the key to Olympia's overall strategy" to prevent expertise from leaving the company. This goal was not easily achievable since Olympia continued to be reliant on HighTech as the only resource provider for Emperor in Australia. The other goal was the delivery of the system on time and budget. Consequently Olympia-online was now developed under a stringent project governance and management regime. The emerging situation resulted in three partially overlapping actor-networks: a Steering Committee, a development, and a Brokers actor-network.

A Steering Committee consisting of stakeholders from the GI Business Division, the Strategy and Planning Division, as well as ISD, was created. The Steering Committee was financially responsible for the project and thus primarily concerned with timeframes and costs. According to a team member, Phase 2 "focused disproportionately on short-term issues and cost considerations, at the expense of long-term quality and functionality". This, in his view, stemmed from the Steering Committee via the Business Project Manager and the IS Project Manager, two new roles, who were responsible for short term goals - the system's delivery on time and on budget, but "seemed not concerned with the system's objectives in the long term". 
The emerging Steering Committee actor-network grew more aligned with the commitment to impose tighter control over the Olympia-online project, keen not to repeat the mistakes from Phase 1. At the same time its relations with the development network deteriorated, leaving few options for interaction. In the meantime the development actor-network continuously reconfigured. Continued problems with Emperor and inadequate resources as requests for additional resources were rejected by the Steering Committee increased tensions and prevented its stabilization. In Phase 2 again the Olympia development team had not enough time and resources to design a modular architecture based on which all subsystems would be developed including future system expansion. The tight budget control and insistence on the planned timeline by the IS Project Manager increased tensions and did little to resolve the key problems in the development of the system.

A Brokers' actor-network emerged and grew strong throughout Phase 2. Major efforts and resources were allocated to redesigning Olympia-online to serve brokers due to the Business Experts' continued parallel engagement in the development actornetwork and with the broker community. They successfully translated the project objectives to be aligned with their own and the broker community interests. Their involvement and influence ensured that the system was not implemented until a sufficient level of functionality and quality required by brokers had been delivered. While this caused tensions with the IS Project Manager "who was constantly pushing for fast delivery" the engagement of the Business Experts resulted in the inscription of the brokers' views and the translation of their interests in Olympia-online leading to a strong alignment between the system and the broker community and to a network stabilization. The quality of the resulting Olympia-online was, as the Business Expert liaising brokers confirmed, exceptional. This ensured that Olympia-online continued and enhanced its market success. This was acknowledged by a Senior GI Business Manager. However, he also said that the project overran, costed too much, and didn't deliver the expected internal functionality.

This view prevailed in the Steering Committee actor-network despite attempts of alignment by the two Business Experts to convince the Steering Committee about the system's market success. While they were initially enthusiastic about the Olympiaonline development, the GI business managers did not engage with the Phase 2 development, as their enrolment in that actor-network became weaker rather than stronger. The reports to the Steering Committee by the IS Project Manager, providing the key relations with the development network, did not indicate early enough that Phase 2 would be delayed and over budget, nor did they indicate that the internal functionality would not be delivered. The managers' view was that they had pretty regular requirements for the system's core internal functionality, management and operational reporting, that "any IS would normally deliver". Their requests were not translated into the system. When the system at the end of Phase 2 did not deliver the requested functionality and when it became evident that it was again over time and over budget, there was no doubt in the Steering Committee network that the Phase 2 Olympiaonline was an "obvious failure". The GI Business Division, ultimately responsible for funding, withdrew their support and the Steering Committee did not approve plans for building Olympia-online further. This decision might jeopardise Olympia's market position and a loss of competitive advantage. 


\section{How Olympia-Online became Both a Success and a Failure}

The conflicting assessments of Olympia-online cannot be explained within existing perspectives. Taking the rationalist perspective (DeLone and McLean 1992, 2003) (see Table 1) one would expect that 'senior management support' evident in most part of the project is a good predictor of Olympia-online success. However this factor was probably more directly linked to system failure: GI managers support led to the decision to purchase the license that played a major role in the production of system failure. Another expected success factor, 'strict management control', evident in Phase 2, can also be associated more with the failure than the success. Circumstances and dynamics of organisational processes in any non-trivial IS development are so complex that a simple explanation of causally linked factors does not make much sense.

The process perspective would reveal organizational and socio-technical processes that led to successful innovation in selling insurance products and the brokers' interaction with the company, therefore leading to success. It would also reveal many technical flaws in designing Olympia-online that led to failure. The perspective however cannot deal with ambiguous and changing assessments nor with contradicting outcomes - Olympia-online is neither abandoned nor supported for future development. While the process perspective does not attempt to provide an objective account of IS success and failure it still sees them as discrete and irreversible 'outcomes', resulting from certain organisational and sociotechnical processes.

The social constructivist perspective would explain how both the success and failure of Olympia-online were socially constructed. From this perspective the stories and narratives of relevant social groups, GI managers, developers, and brokers, can be seen as producing the discourses of failure as well as the discourses of success. The Olympia-online system is perceived and interpreted differently by these relevant social groups, thereby implying its interpretive flexibility. Pluralist views and different Olympia-online assessments thus are perspectival in nature. The problem with social constructivism is that excessive power is attributed to representations and words and discourses of IS success and failure without recognising their material foundation.

\subsection{Reconceputalizing the Success and Failure of IS}

The sociomaterial perspective considers IS success and failure as relational effects, that do not exist by themselves but are endlessly generated in actor-networks (Law 2004). It directs attention to the different practices enacted by Olympia-online development and use and to the ways in which such enactments produced multiple realities of system success and failure. The sociomaterial perspective is premised on a conception of technology and IS as non-human actors which are constitutively entangled with human actors in webs of relations in situated practices (Orlikowski 2007). Instead of investigating how one impacts on the other, we experience these actors' worlds. This enables us to see how IS success and failure are produced by sociomaterial dynamics in actor-networks. Actor-networks are not clearly distinguishable entities, they are (parts of) sociomaterial entanglements and become visible through agential cuts.

The production of Olympia-online success in the Brokers' actor-network can be traced to the Business Experts' engagement to translate the brokers' needs and 
interests into the development of the Olympia-online software. Their engagement became even more prominent in Phase 2 as they forged close interaction and further alignment between brokers, the development team, the Olympia-online software and Horizon. Emerging through these processes was the brokers' network which had an evident overlap with the development network; they shared actors and relations that assisted their mutual alignment. Being heavily engaged in the system testing, the brokers expressed their high appreciation for the system quality. The new reality of Olympia-online enacted in the brokers' actor-network resulted from transformation of their work practices and their innovative ways of customizing products for customers and transacting business with Olympia. The wide adoption of these practices created market success and tangible benefits for Olympia. The production of success was not only the result of the brokers' attribution of meanings and discursive construction of Olympia-online in their practices. It was also material and technological; the development actor-network and the overlapping brokers' actor-network jointly created such a sociomaterial constellation that the development of Olympia-online and its enactment in the brokers' practices became closely connected, mutually triggering changes in each other. The brokers were part of and contributors to the sociomaterial constellation as they innovated their practices through the appropriation of Olympia-online and based on this experience suggested changes in the system.

A sociomaterial entanglement is a network arrangement, a mangle of practice, which implies inseparability of the social, discursive and the material, technological that are "mutually and emergently productive of one another" (Pickering 1993, p. 567). They are inseparable in the overall reconstruction of organisational reality, but become locally separable through agential cuts. It is in fact very difficult, sometimes impossible, to separate the social, discursive from the material, technological production of the Olympia-online reality in the brokers' practices. They are intimately fused in the brokers' situated experiences and their enactment of new and innovative practices in the sociomaterial constellation emerging in the brokers' actor-network. The sociomaterial constellation that fused together multiple meanings and material technologies of Olympia-online development, its software proper, and the brokers' practices, was created simultaneously in both networks. The two networks were porous enough to co-create such a sociomaterial constellation that in the brokers' network produced the reality of the Olympia-online success in the market.

The trajectory and dynamics of the Olympia-online development actor-network are even more complicated. The complexity of this network arose due to enrolment of numerous actants, complex translation processes and continuous building and reconfiguring of relations during both phases. The key enrolment in Phase 1 of the development network was that of the rule-engine Emperor. Due to Emperor's central role in modelling insurance products and related business rules the Olympia-online software became intimately dependent on it. With the purchase of the Emperor License, the actor-network further increased its dependence on Emperor with significant ramifications.

When the Olympia team engaged with Emperor's rule-based Engine - while designing and testing the software's structure, processes, user interface, security procedures, etc. - they experienced severe limitations in modelling insurance products. The built software was therefore cumbersome and complex. The sociomaterial constellation that emerged in the relations between the Olympia team, the HighTech team, 
Emperor, the mainframe, and the business experts only allowed for a limited and ineffective translation of insurance products and business rules into the Olympia-online software. Emperor's agency in this translation process was not only a social construction. It was relationally and materially enacted through the project managers', the architects' and the developers' practices within this sociomaterial entanglement which did not leave them with much design alternatives, allowing only particular design practices, and leaving traces in the designed structures, application programs, and processes. This is congruent with Quattrone and Hopper's (2006) findings that agency of technology extends beyond human responses to it and that it resides in the chain of relations between the actants.

While after Phase 1, the general consensus amongst Olympia-online development team members was that Emperor should be abandoned this became politically unfeasible due to the money spent on Emperor licensing. Furthermore, the more code the development team developed based on Emperor the less likely they were to abandon it. Dependency on Emperor in the development network became thus more and more irreversible making it almost impossible to "go back to a point where alternative possibilities exist[ed]" (Walsham and Sahay 1999, p. 42). The increasing irreversibility of the development actor-network made its sociomaterial entanglement increasingly more critical and consequential for the final system.

Another important dynamics arose through this network's relations with the Steering committee network. During Phase 2 the Olympia team requested further resources arguing that the complexity of Olympia-online and the problems with Emperor necessitated much more than initially planned. However, no additional resources were approved by the Steering Committee. The very objective of creating this committee and the two new management roles in Phase 2 were to enforce strict budget control and the delivery deadline. This objective was firmly held by the committee and the network formed around it. Without additional resources the team was not able to deliver full functionality. Seeing the functionality for the brokers as a priority the team, to some extent influenced by the Business Experts, the development team allocated all their resources to develop this functionality first. It however meant delaying the development of functionality required by the GI managers. This was not known outside this network and was first reported by the IS Project Manager to the Steering Committee just before the end of Phase 2.

Although the Olympia-online development was not completed and its actornetwork did not stabilize Phase 2 was concluded as the project was already over time and budget. At this point in time the developers were fully aware of the technical deficiency of the Olympia-online design. Highly limited resources and the complexity of the design had prevented a radical change of the architecture in Phase 2. It was a series of sociomaterial entanglements that we traced during this network reconfiguration in Phases 1 and 2, which produced the final Olympia-online system. But this did not happen in isolation. Relations emerging in the other two networks, partially overlapping with the development network, played their role as well.

The Steering Committee actor-network had a direct influence on the IS Project Manager and the Business Project Manager that were charged with the responsibility to impose stringent project and budget control. This was a major relation between the Steering Committee actor-network and the development network. By purchasing the Emperor license and thereby effectively enrolling it in the development actor-network 
the Steering Committee showed their commitment and support for the project. However, the relations between the two networks became weaker. Attempts by the Business Experts to strengthen the ties with the Steering Committee and align its network's objectives with that of the development network had not been doing well. In Phase 2 the two networks emerged less connected and less aligned than before. The market success of Olympia-online was acknowledged by the GI managers but this only confirmed their appreciation for Emperor. The sociomaterial entanglement within the Steering Committee actor-network was enacted by the managers' preoccupation with budget control and deadlines, sporadic relations with the HighTech team and reports by the IS Project Manager, including the final one informing them that the expected functionality requested by GI managers was not going to be delivered, and that the development was over time and budget. There were no relations with the development team or the application software. The resulting failure verdict seemed an inevitable outcome.

This analysis suggests the relevance of the emergence and reconfiguration of actornetworks understood as sociomaterial entanglements for the comprehension of different enactments and assessments of IS. The success and the failure of Olympia-online were more than different perceptions and social constructions by relevant social groups. Due to the assembling and reconfiguring of the actor-networks multiple sociomaterial constellations emerged. The sociomaterial entanglements involved inseparable and mutually constituting discursive and material constructions which we turned visible through agential cuts. The analysis shows it is not just humans who discursively construct the success or failure, nor is it only material resources, technology and material components of an IS such as internal and external functions, modular structures or platforms that exert influence on human actors thus causing the success or failure, it is the emergence of the(ir) sociomaterial relations within which they encounter each other and through which the discursive and the material technology are entangled and preformed, f. ex. through the purchase of licenses or resource constraints, and construct a success or a failure. Agential cuts turn these entanglements visible and render them locally separable. The success and failure of IS are made in and by multiple actor-networks.

\subsection{Multiple IS Realities and IS Success and Failure}

Olympia-online was continuously re-enacted in practices of different actor-networks, which produced multiple, alternative realities. The recognition of multiplicity of IS realities in practice is conceptually different from plurality implied by social constructivism (Law 2004; Mol 1999). Plurality assumes a single reality that is observed, perceived and interpreted differently by different social groups, hence plurality of views and assessments (Bartis and Mitev 2008; Wilson and Howcroft 2005). Multiplicity implies multiple realities that are "done and enacted rather than observed. Rather than being seen by a diversity of watching eyes while itself remaining untouched in the centre, reality is manipulated by means of various tools in the course of a diversity of practices" (Mol 1999, p. 77, emphasis in the original). Enactments of the Olympia-online development and use in different practices within the three different actor-networks produced multiple realities. The resulting co-existence of multiple 
Olympia-online realities created a problem Olympia was incapable of resolving: it was stuck with contradicting assessments; unable to reconcile this multiplicity. The decision regarding investment into Olympia-online's further development was stalled. Beyond the project's fate Olympia's relationship with brokers, its market position, and ultimately the company's future are at stake. Such a situation raises the question: what could be done differently?

As conditions of creation and emergence of actor-networks are not given but created and re-created, realities might be done in other ways; different sociomaterial entanglements of an IS development "might make it possible to enact realities in different ways" (Law 2004, p. 66). Enacting an IS and performing a reality one way or another can thus be open for debate. Understanding the Olympia-online case may help both practitioners and researchers gain deeper insights into the production of the IS realities of success and failure, help undo some deeds, and perhaps prevent failure. The trajectories of the actor-networks in Phase 1 and 2 reveal the conditions for possible options at any point in time, with some actions and reconfigurations playing a more significant role than others.

The reality of Olympia-online's success in the market was produced by the brokers' network; key were the actions of the Business Experts who actively engaged in translating the brokers' needs into the IS and attracted brokers to engage in testing and who contributed to the resource allocation for testing Olympia-online's usability. This strengthened the relations between development and brokers networks thus producing success. However it hid the resource allocation to meet the brokers' needs. While it ensured high quality functionality for the brokers it withdrew resources from development of internal functionality relevant for the GI managers. On reflection, this could have been different, choosing perhaps a more balanced resource allocation.

The reality of Olympia-online enacted by the Steering Committee actor-network resulted in the assessment of failure. Neither the GI Managers nor other members of the committee ever questioned or revised the initial prediction of the project resources and duration for Phase 2 despite new evidence about the increasing complexity of the project and a need for larger resources to complete the project - contained in reports submitted to the Steering Committee. During Phase 2 the committee actor-network became more stabilized and at the same time more disconnected from the development actor-network. Consequently this network was narrowed and steadfast, leaving no options for alternative considerations. Despite the evidence of market success, Olympia-online for them was a failure. The failure verdict was natural and obvious: it was seen as "based on hard facts" as "the system was over time and over budget" and "its internal functionality was not delivered". However the use of these particular measures of project success/failure was never explicated. Options to discuss different assessment criteria and to question and revise initial estimates of required resources and time were not considered. A possibility of questioning assumptions regarding a stable and robust infrastructure had not been entertained. This might have led to opportunities for enactment of a different reality and for taking different action regarding Olympia-online's future development.

Finally, for the development actor-network the HighTech enrollment was highly consequential with Emperor playing a key role in the Olympia-online development. It was plagued by the developers' battle with Emperor and its integration with the mainframe. It engaged unexpectedly large resources thus contributing to prolonged 
delivery and missing functionality of the final system. Choosing an option to reject working with Emperor, even after the license was purchased, would have changed the network's trajectory; other options included contract termination with HighTech and the enrollment of other partner companies, fulfillment of the initial objectives to develop a modular architecture, and a more balanced resource allocation to deliver full system functionality.

The discussion reveals multiple and largely incoherent realities within the identified actor-networks. It reveals some possibilities and options to make different choices at particular points in time and enact realities in different ways. Some of these options still existed but were not seen by the actors when the decisions concerning Olympia-online's future were made. To see them actors needed to reflect on and understand the ways in which multiple Olympia-online realities were enacted in different practices. The more all stakeholder succeed in understanding the making of these multiple realities the more open they might become for re-negotiation and reconciliation of multiple assessments in the light of strategic objectives and market implications.

\section{Conclusion}

This essay proposes a sociomaterial perspective on IS success and failure. The investigation of the Olympia-online case, resulting in concurrently contradicting and unreconciled assessments, provided an opportunity to demonstrate a distinct theoretical and practical contribution of the sociomaterial perspective to the understanding of IS success and failure.

The sociomaterial perspective focuses on IS enactments in practices that are not only performed discursively but also and inevitably materially through sociomaterial relations involving material encounters which would be only partially understood by social constructivism. The sociomaterial perspective reveals how the success and the failure of IS are produced as relational effects in and by actor-networks. It draws attention to the contingently enacted realities of IS within emergent actor-networks of IS development and use in practice. Through the analysis of reconfigurations of the actor-networks, we illustrate how multiple realities of system success and failure have been produced concurrently. The lessons from the case teach us that there are options to make different choices along the way and to re-enact realities differently (Law 2004).

In addition, we examined how the networks could have been reconfigured differently. An actor-network "is not a network of connecting entities which are already there but a network which configures ontologies." (Callon 1999, pp.185). What an enrolment would do or change in an actor-network, is rarely known or well understood when it happens. This suggests further research. There are many open questions: How can multiple and contradicting realities be reconciled and and thus failure be prevented? How can premature stabilization of an actor-network be avoided and how can greater congruence between relevant actor-networks be enabled? How can alternative options for enacting IS reality differently be identified?

Finally, conducting and presenting an ANT study poses many challenges. Following the actors and investigating the relations within actor-networks by making agential cuts 
reveal complexities that resist clear and simplified presentations and a linear story typically expected of academic writing. An ANT study emphasises flow and change as key to understanding the being and doing of actors as well as the emergence and reconfiguration of actor-networks. As this is not easily communicated we produced snapshots and momentary outside views of actors' worlds at different points in the project timeline. These are inherently limited by the nature of the printed medium and a potential domain of future research might explore alternatives genres and new electronic media in presenting actor-networks and achieved research results.

Acknowledgements. We like to recognize Rebecca Abrahall who as a research student collected the data which build the empirical basis for our analysis.

\section{References}

Barad, K.: Posthumanist Performativity: Toward an Understanding of How Matter Comes to Matter. Signs: Journal of Women in Culture and Society 28(3), 801-831 (2003)

Bartis, E., Mitev, N.: A Multiple Narrative Approach to Information System Failure: A Successful System that Failed. European Journal of Information Systems (17), 112-124 (2007)

Bijker, W.E.: Do Not Despair: There Is Life after Constructivism. Science, Technology and Human Values 18(1), 113-138 (1993)

Callon, M.: Some Elements of a Sociology of Translation: Domestication of the Scallops and the Fisherman of St. Brieuc Bay. In: Law, J. (ed.) Power, Action and Belief: A New Sociology of Knowledge? Sociological Review Monograph, vol. 32, pp. 196-233. Routledge and Kegan Paul, London (1986)

Callon, M.: Actor-Network Theory: the Market Test. In: Law, J., Hassard, J. (eds.) Actor Network and After, pp. 181-195. Blackwell (1999)

Currie, W.: Computerizing the Stock Exchange: A Comparison of Two Information Systems. New Technology, Work and Employment 12(2), 9-36 (1997)

DeLone, W.H., McLean, E.R.: Information System Success: The Quest for the Dependent Variable. Information Systems Research 3(1), 60-95 (1992)

DeLone, W.H., McLean, E.R.: The DeLone and McLean Model of Information System Success: A Ten Year Update. Journal of Management Information System 19(4), 9-31 (2003)

Fincham, R.: Narratives of Success and Failure in Systems Development. British Journal of Management (13), 1-14 (2002)

Holmström, J., Robey, D.: Understanding IT's organizational consequences: An actor network theory approach. In: Czarniawska, B., Hernes, T. (eds.) Actor-Network Theory and Organizing, pp. 165-187. Liber, Stockholm (2005)

Kautz, K., McMaster, T.: Introducing Structured Methods: An Undelivered Promise? A Case Study. Scandinavian Journal of Information Systems 6(2), 59-78 (1994)

Latour, B.: Science in Action: How to Follow Scientists and Engineers through Society. Harvard University Press, Cambridge (1987)

Latour, B.: Technology is Society Made Durable. In: Law, J. (ed.) A Sociology of Monsters. Essays on Power, Technology and Domination, pp. 103-131. Routlegde (1991)

Latour, B.: Reassembling the Social: An Introduction to Actor-Network-Theory. Oxford University Press (2005)

Law, J.: The Anatomy of Socio-Technical Struggle: The Design of the TSR2. In: Elliot, B. (ed.) Technology and Social Processes. Edinburgh University Press, Edinburgh (1988) 
Law, J.: Notes on the Theory of the Actor-Network: Ordering, Strategy and Heterogeneity. Systems Practice 5(4), 379-393 (1992)

Law, J.: After Method: Mess in Social Science Research. Routledge, London (2004)

Lee, G., Xia, W.: The Ability of Information Systems Development Project Teams to Respond to Business and Technology Changes: A Study of Flexibility Measures. European Journal of Information Systems (14), 75-92 (2005)

Luna-Reyes, L.F., Zhang, J., Gil-García, J.R., Cresswell, A.M.: Information Systems Development as Emergent Socio-Technical Change: A Practice Approach. European Journal of Information Systems (14), 93-105 (2005)

Lyytinen, K., Hirschheim, R.A.: Information Systems Failure: A Survey and Classification of The Empirical Literature. In: Zorkoczy, P.I. (ed.) Oxford Surveys in Information Technology, vol. 4, pp. 257-309. Oxford University Press, Oxford (1987)

McLean, C., Hassard, J.: Symmetrical Absence/Symmetrical Absurdity: Critical Notes on the Production of Actor-Network Accounts. Journal of Management Studies 41(3), 493-519 (2004)

McMaster, T., Wastell, D.: Success and Failure Revisited in the Implementation of New Technology: Some Reflections on the Capella Project. In: Innovation for Adaptability and Competitiveness, Proceedings of IFIP WG8.6 Working Conference, Leixlip, Ireland, Boston. Kluwer (2004)

McMaster, T., Vidgen, R.T., Wastell, D.G.: Technology Transfer - Diffusion or Translation? In: McMaster, T., Mumford, E., Swanson, E.B., Warboys, B., Wastell, D. (eds.) Facilitating Technology Transfer Through Partnership: Learning From Practice and Research, pp. 64-75. Chapman and Hall, London (1997)

Miller, P.: The Multiplying Machine. Accounting, Organisations and Society 21(7/8), 615-630 (1996)

Mitev, N.: More than a failure? The computerized reservation systems at French Railways. Information Technology and People 9(4), 8-19 (1996)

Mitev, N.: Are Social Constructivist Approaches Critical? The Case of IS Failure. In: Howcroft, D., Trauth, E. (eds.) Handbook of Critical Information System Research: Theory and Application, pp. 70-103. Edward Elgar, Cheltenham (2005)

Mol, A.: Ontological Politics: A Word and some Questions. In: Law, J., Hassard, J. (eds.) Actor Network Theory and After, Blackwell and the Sociological Review, Oxford and Keele, pp. 74-89 (1999)

Nelson, M.R., Ravichandran, T.: Understanding the Causes of IT Project Failures in Government Agencies. In: 7th Americas Conference on Information Systems, AMCIS, pp. 1451-1453 (2001)

Orlikowski, W.J.: Sociomaterial Practices: Exploring Technology at Work. Organization Studies 28(9), 1435-1448 (2007)

Orlikowski, W.J., Scott, S.V.: Sociomateriality: Challenging the Separation of Technology, Work and Organization. In: The Academy of Management Annals, vol. (2), ch. 10, pp. 433-474 (August 2008)

Pickering, A.: The Mangle of Practice, Agency and Emergence in the Sociology of Science. American Journal of Sociology 20(2), 241-261 (1993)

Quattrone, P., Hopper, T.: What Is IT? SAP, Accounting, and Visibility in a Multinational Organisation. Information and Organization (16), 212-250 (2006)

Sauer, C., Southon, G., Dampney, C.N.G.: Fit Failure and the House of Horrors: Toward a Configurational Theory of IS Project Failure. In: Proceedings of the 18th International Conference on Information Systems, ICIS, Atlanta, Georgia, pp. 349-366 (1997) 
Sauer, C.: Why Information Systems Fail: A Case Study Approach. Alfred Waller, Henley-onThames (1993)

Vidgen, R., McMaster, T.: Black Boxes: Non-Human Stakeholders and the Translation of IT Through Mediation. In: Proceedings of the IFIP TC8 WG 8.2 International Conference on Information Systems and Qualitative Research, pp. 250-271 (1997)

Walsham, G.: Actor-Network Theory and IS Research: Current Status and Future Prospects. In: Proceedings of the IFIP TC8 WG 8.2 International Conference on Information Systems and Qualitative Research, pp. 466-480 (1997)

Walsham, G., Sahay, S.: GIS for District-Level Administration in India: Problems and Opportunities. MIS Quarterly 23(1), 39-65 (1999)

Wilson, M., Howcroft, D.: Power, Politics and Persuasion in IS Evaluation: A Focus on 'Relevant Social Groups'. Journal of Strategic Information Systems (14), 17-44 (2005) 